
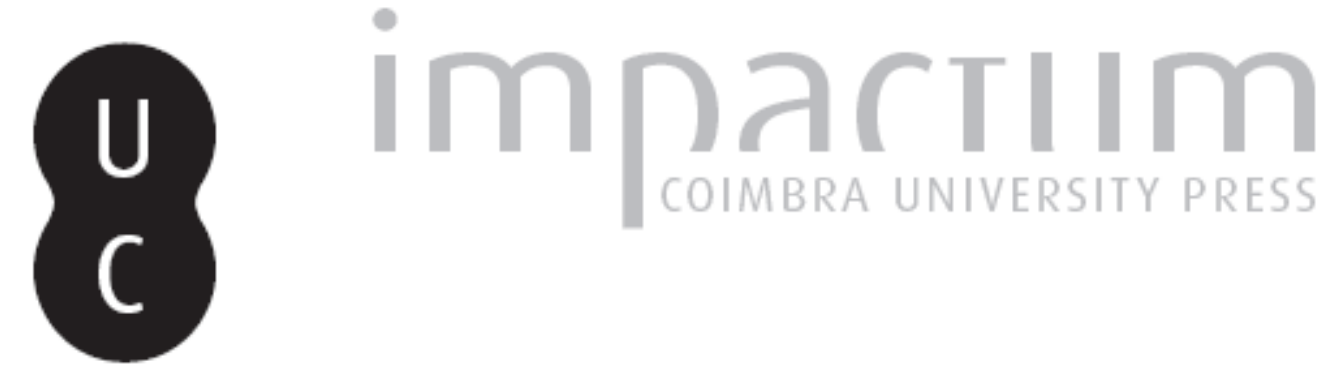

\title{
A colecção egípcia do Museu de História Natural da Universidade do Porto: «os mistérios do além no Antigo Egipto»
}

Autor(es): $\quad$ Sousa, Rogério Ferreira de

Publicado por: Centro de História da Universidade de Lisboa

URL persistente:

URI:http://hdl.handle.net/10316.2/23847

DOI:

DOI:http://dx.doi.org/10.14195/0871-9527_18_14

Accessed : $\quad$ 26-Apr-2023 06:42:59

A navegação consulta e descarregamento dos títulos inseridos nas Bibliotecas Digitais UC Digitalis, UC Pombalina e UC Impactum, pressupõem a aceitação plena e sem reservas dos Termos e Condições de Uso destas Bibliotecas Digitais, disponíveis em https://digitalis.uc.pt/pt-pt/termos.

Conforme exposto nos referidos Termos e Condições de Uso, o descarregamento de títulos de acesso restrito requer uma licença válida de autorização devendo o utilizador aceder ao(s) documento(s) a partir de um endereço de IP da instituição detentora da supramencionada licença.

Ao utilizador é apenas permitido o descarregamento para uso pessoal, pelo que o emprego do(s) título(s) descarregado(s) para outro fim, designadamente comercial, carece de autorização do respetivo autor ou editor da obra.

Na medida em que todas as obras da UC Digitalis se encontram protegidas pelo Código do Direito de Autor e Direitos Conexos e demais legislação aplicável, toda a cópia, parcial ou total, deste documento, nos casos em que é legalmente admitida, deverá conter ou fazer-se acompanhar por este aviso.

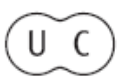



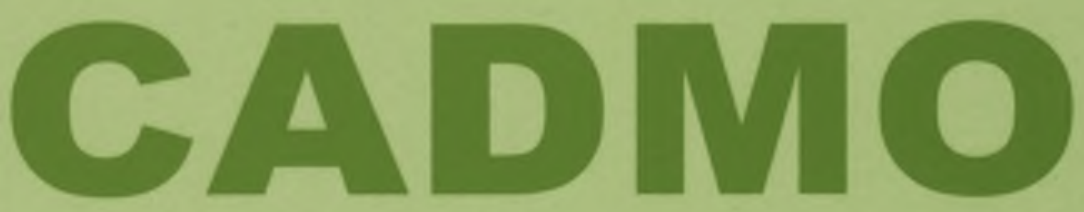

Revista de História Antiga

\author{
Centro de História \\ da Universidade de Lisboa
}

18

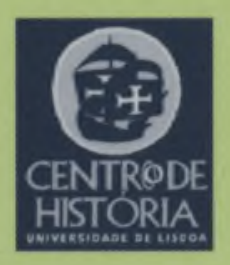

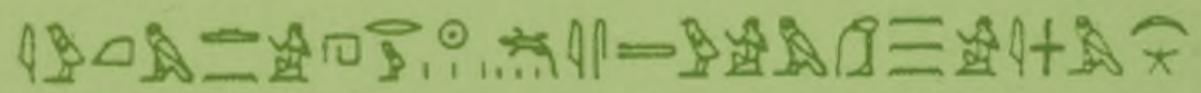

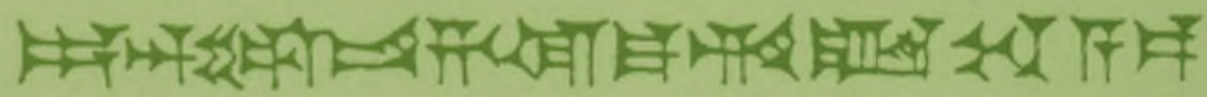

MHNIN AEI $\Delta$ E $\Theta E A ~ \Pi H \Lambda H I A \triangle E \Omega$ 


\section{A COLECÇÃO EGÍPCIA DO MUSEU DE HISTÓRIA NATURAL DA UNIVERSIDADE DO PORTO: "OS MISTÉRIOS DO ALÉM NO ANTIGO EGIPTO»}

A colecção egípcia do Museu de História Natural da Universidade do Porto foi o pretexto para a exposição temporária exibida nas instalações da Casa-Museu Teixeira Lopes de 26 de Fevereiro a 26 de Março de 2008. A referida colecção é a mais modesta das quatro principais colecções egípcias existentes em Portugal. O mais importante destes núcleos é, sem dúvida, o pequeno acervo conservado no Museu da Fundação Calouste Gulbenkian, que conta entre as suas peças com diversas preciosidades, algumas com projecção internacional, como é o caso do notável busto de Senuseret III, das delicadas estatuetas de madeira da XVIII dinastia, ou até da esplêndida máscara de prata dourada da Época Baixa. Segue-se a colecção egípcia do Museu Nacional de Arqueologia, que conta com cerca de quinhentas antiguidades. Embora recentemente constituída, a colecção egípcia do Museu da Farmácia (para a qual se prevê a aquisição de mais algumas peças) conta já com 103 objectos cuidadosamente seleccionados de acordo com a temática específica do Museu, entre os quais figura um sarcófago policromado em excelente estado de conservação. Finalmente, a encerrar este prestigiado grupo de acervos museológicos, figura o espólio egípcio do Museu de História Natural com as suas 103 antiguidades.

\section{A museologização das peças}

Do ponto de vista estético a exposição foi bem concebida, apresentando uma desejável uniformidade dos critérios de exposição. O espaço, embora pequeno, levando em conta o número de vitrinas apresentadas, foi harmoniosamente gizado, tendo como eixo organizador 
a bela máscara funerária dourada exibida na parede central da sala. A iluminação, sem perturbar o ambiente de penumbra envolvente, faz emergir os objectos da escuridão, criando um ambiente propício à contemplação das veneráveis antiguidades exibidas. Decepcionante, no entanto, foi a estranha inclusão de uma inusitada caixa de escaravelhos na mesma vitrina onde se apresentam os soberbos escaraveIhos do coração, objectos que, para além de terem um grande significado mágico e ritual, são de uma execução notável. Esta caixa, oriunda das colecções de zoologia do Museu de História Natural, figuraria meIhor numa janela rasgada nas paredes com propósitos pedagógicos, evitando assim atribuir um estatuto idêntico às antiguidades e à caixa de apresentação pouco atraente. Ainda em relação aos escaravelhos do coração, também não se compreende por que razão não foi mostrada a base de um destes exemplares de modo a revelar aos olhos do visitante o texto que lá está gravado: o capítulo 30 do "Livro dos Mortos", um dos textos mais importantes desta composição funerária. É uma prática comum recorrer a um espelho colocado sob a peça em questão para permitir a visualização total do objecto o que, infelizmente, não foi feito.

\section{As legendas}

As legendas que acompanham as peças apresentam muitas graIhas e lacunas. As cifras escolhidas para a datação da Época Pré-dinástica oscilam indiferentemente entre 3500 a 3300 a. C. (objectos 9, 14 e 15) ou 4500 a 3300 a. C. (objecto 4), ao contrário do critério adoptado para as restantes épocas que são sempre assinaladas tendo em conta o mesmo intervalo de tempo. Em alguns casos, há mesmo erros de datação. É o caso do espelho (objecto 30), datado entre o Império Novo e a Época Baixa. A legenda apresenta, no entanto, o intervalo temporal compreendido entre 4000 a. C. (uma cifra que diz respeito ao Pré-dinástico!) e 332 a. C. Outra cifra incorrecta, e que é insistentemente apresentada, reporta-se à datação do período ptolemaico. Em primeiro lugar impõe-se uma observação relacionada com a terminologia utilizada. Na literatura egiptológica portuguesa diferencia-se de modo muito claro a designação de época e de período. Tendo em conta esta diferenciação, normalmente considera-se que a Época Greco-Romana (332 a. C.-395 d. C.) se divide em três períodos: o período alexandrino (332-305 a. C.), o período ptolemaico (305-30 a. C.) 
e o período romano (30 a. C.-395 d. C.). As legendas, porém, referem sempre "Época Ptolemaica», situando-a, o que é pior, num período temporal errado: 332-32 a. C. Sem que se compreenda a razão para escolher a cifra 32 a. C. para o fim do período ptolemaico, a verdade é que esta se encontra em contradição com todas as cronologias oficiais que, pelo contrário, advogam a data de 30 a. C. para o fim do referido período, uma vez que é nessa data que se verificou o suicídio da famosa rainha Cleópatra VII Filopator (51-30 a. C), a que se seguiu a integração definitiva do Egipto no Império Romano.

As peças expostas com os números 17 e 18 são referidas como sendo "pré-históricas", o que não parece ser a interpretação mais correcta. É mais certo que se trate de típicos recipientes conhecidos pela designação de "vasos de boca negra" oriundos de Kerma, na Núbia, datados de inícios do II milénio a. C. Por outro lado, informa-se o visitante que a peça 67 é um "vaso canópico"... Será que o visitante fica esclarecido? O que é um vaso canópico?... Mais valia, com toda a simplicidade e a obviedade pedagógica que se requer em exposições públicas deste tipo, aludir à peça como sendo um vaso de vísceras.

O mesmo acontece na vitrina que expõe algumas estatuetas funerárias, sendo os visitantes "esclarecidos" que se trata de "uchebtis ou chauabtis"! O que querem dizer, para o público, estas designações? Nada é avançado a este respeito, o que muito se lamenta, pois assim perde-se a oportunidade de explicar a diferença entre chauabtis e uchebtis, que são estatuetas funerárias de épocas diferentes.

\section{Os textos da exposição}

\subsection{As lacunas}

Infelizmente o sentido da exposição não corresponde ao benefício da montagem. Tratava-se, de acordo com o título aceite, de integrar um espólio que a isso bem se prestava, num projecto de esclarecimento cultural, suficientemente abrangente do significado da carismática percepção do Além no Antigo Egipto. Os itens da exposição teriam de ser explicitamente coerentes, divulgando informação actualizada que permitisse a real apreensão do significado dos objectos - o que os textos apresentados, supostamente explicativos, não fazem. 
Em primeiro lugar não se compreende por que razão nenhum dos textos e inscrições patentes em inúmeras peças foi traduzido e divulgado ao público. Também se afigura imperdoável a ausência de referências ao próprio "Livro dos Mortos". Afinal existe uma tradução portuguesa desta importante compilação de textos mágicos e, para a maior parte do público, o "Livro dos Mortos» é uma obra presente nas suas referências culturais, pelo que se afiguraria pertinente esclarecer o visitante acerca deste importante livro que condensa em si todo o poderoso imaginário associado às crenças egípcias no Além. E não se pode argumentar que a colecção não possui textos do "Livro dos Mortos». Eles estão presentes quer no escaravelho do coração (capítulo 30), quer nas estatuetas funerárias (capítulo 6). Quanto aos chauabtis, como já foi referido, nada é dito acerca destes importantes artigos funerários que, em virtude do seu próprio peso na colecção egípcia do Museu, bem poderiam ser o ponto de partida para uma elucidativa e educativa incursão nas crenças do Além que conduziria inclusivamente o visitante a descobrir uma das raízes para o imaginário ocidental associado ao Paraíso dos justos, uma crença que ainda hoje sobrevive em muitas religiões da actualidade. De facto, embora originalmente as estatuetas funerárias tivessem sido criadas com o intuito de munir o defunto com uma "múmia" de substituição, rapidamente estes objectos foram investidos com a função de "responder" ao chamamento do defunto. Esta função é tão nuclear que está na origem da designação de uchebti que é atribuída a estes objectos na literatura egiptológica. $\mathrm{Na}$ verdade, embora nenhuma destas úteis explicações seja proporcionada ao visitante, o termo uchebti significa "O que responde", e faz alusão aos trabalhos que o defunto devia desenvolver nos Campos de laru, os campos míticos do Além reservados aos justos. O "Livro dos Mortos" descreve, deste modo, a felicidade que aí se vivia, como se pode ler no capítulo 110: "Aqui como e bebo, aqui trabalho e aqui ceifo, aqui copulo e faço amor».

Os Campos de laru, o paraíso egípcio, eram, deste modo, concebidos à imagem e semelhança do próprio Egipto terreno. Do ponto de vista cultural, é, portanto, extremamente significativo que o mundo idílico proporcionado aos justos fosse concebido à imagem da vida que decorria nas margens do Nilo. As alusões à actividade sexual que decorria nos Campos de laru destinavam-se a acentuar as conotações de fertilidade associadas a estas paragens míticas onde os poderes vitais do defunto se regeneravam. Neste enquadramento conceptual, os uchebtis vinham libertar o defunto dos trabalhos do campo 
para que este se pudesse entregar às restantes actividades, bem mais prazeirozas. Constituídas por vários materiais e feitas em diferentes épocas, as estatuetas funerárias da colecção permitiam também explorar a evolução patente nestes objectos ao longo do tempo. Nenhum destes recursos patrimoniais foi aproveitado e perdeu-se a oportunidade para instruir os visitantes acerca destes sugestivos objectos que testemunham um capítulo extremamente fértil do imaginário da morte no Antigo Egipto.

Ao contrário, o "Egipto Copta», que figura na colecção com um único objecto, mereceu um texto explicativo, sem que a sua relação com os "Mistérios do Além» fosse, infelizmente, clarificada. Também não há qualquer texto que contextualize as "estrelas" da exposição, a bela máscara dourada, o sarcófago e a múmia, como seria de esperar. Lamentavelmente também não há qualquer referência ao túmulo, nem ao significado ritual e simbólico que as estruturas funerárias possuíam no antigo Egipto.

Se o significado dos objectos não foi esclarecido, desejava-se, pelo menos, que a sua função no contexto do enterramento fosse esclarecida. O abundante espólio pré-dinástico, com raízes no Neolítico do vale do Nilo, poderia ser o ponto de partida num percurso pedagógico susceptível de conduzir o visitante às origens da civilização egípcia tendo, por outro lado, como contraponto, a complexidade atingida no Egipto da Época Baixa. Este rico filão de informação foi, como tantos outros, ignorado.

\subsection{Terminologia científica}

Quanto ao rigor científico da terminologia utilizada, os textos de apoio também não dão mostras de credibilidade. No texto «Magia e Amuletos", são incorrectamente grafados alguns amuletos, como o uadj (e não Wadj como se usa na literatura anglo-saxónica) ou o tjet (e não tyet, à espanhola). No texto "Religião egípcia e o culto aos deuses» é referida a "Enéada», em vez de "Enéade». No texto "Vida após a Morte" é apresentada uma afirmação digna de ser citada: "perante Juízes e Divindades o coração do morto era pesado pelo Deus (sic) Anúbis, tendo no outro prato da balança uma pena, símbolo do (sic) Maat». Em egiptologia a palavra "deus» nunca é grafada em caixa alta, um atributo reservado às religiões monoteístas. Mais grave é a expressão, "símbolo do Maat". Impõe-se aqui explicar que maat, 
ou maet, é o termo egípcio que designa a noção de "verdade", «justiça» ou "ordem cósmica». Como qualquer conhecedor da escrita hieroglífica sabe, o feminino é construído com a partícula $t$. A noção de maet ou maat, que aliás é personificada numa deusa, é um conceito feminino, o que parece ser desconhecido pelos redactores daquelas linhas que, deste modo, revelam falhas crassas, não só de conhecimento da escrita hieroglífica, mas também da mais elementar e basilar cultura egiptológica.

\subsection{Conteúdo}

Pior do que um domínio deficiente da terminologia egiptológica, os textos veiculam ideias simplistas e até ingénuas da religião egípcia. No texto "Magia e amuletos", refere-se que o escaravelho "empurrava o sol ao longo do céu durante a noite". Embora as representações iconográficas do percurso nocturno do Sol possam efectivamente representar o escaravelho sagrado com o disco solar entre as patas, qualquer pessoa entendida na iconografia egípcia e na escrita hieroglífica sabe que o escaravelho é o símbolo do deus Khepri, o Sol nascente, e que, quando utilizado como hieróglifo, significa kheper, termo que significa "transformar-se» ou "vir à existência». É pois incorrecto, já para não dizer absurdo, dizer-se que o escaravelho "empurrava o sol ao longo do céu durante a noite", uma vez que o escaravelho representa o Sol em transformação. Afirmações como esta, para além de não traduzirem uma compreensão correcta do pensamento egípcio, desvirtuam a real profundidade dos seus símbolos e dos ensinamentos que the estão implícitos. Assim, embora dirigidos a um público não especializado, a função dos textos de apoio é a de fornecer informação que, embora simplificada, não perturbe a mensagem original.

Questões deste tipo avolumam-se em torno dos textos mais vocacionados para a religião, uma área efectivamente difícil do antigo Egipto. O texto "A religião egípcia e o culto dos deuses" começa por referir "os egípcios acreditavam que no início nada existia, era o caos chamado Nun, tudo era obscuridade até chegar à luz". Embora se refira que no «início nada existia», logo em seguida, se refere que afinal existia o Nun, sem nada afiançar em relação ao verdadeiro alcance do paradoxo da existência e da não existência, fulcral nos mitos egípcios da criação. Em seguida, sem referir qual dos mitos utiliza 
para reger a descrição da criação, o(s) autor(es) destas linhas prosseguem: "A luz dá origem ao primeiro deus e a todos os outros. Aparecem depois os animais e os seres humanos". Não é correcto dizer-se que a luz dá origem ao primeiro deus. Em primeiro lugar, o mundo anterior à criação já é povoado por deuses. Veja-se o caso da Ógdoade de Hermópolis, de Ptah, de Neit ou de Mehetueret, só para citar alguns exemplos. Todos estes deuses são divindades primordiais que antecedem a própria criação do mundo. Estes deuses dão origem ao deus criador, normalmente uma manifestação do Sol, como o deus Atum, que então põe em marcha a criação da luz. A rematar, o texto refere que "os deuses metade homem metade animal são uma das características do mundo egípcio". Poder-se-á dizer, a partir de uma visita superficial às igrejas cristãs, que o cristianismo é uma religião politeísta que adora um deus com forma de cordeiro. Uma afirmação deste teor seria vista por todos os que conhecem esta religião como errónea. Embora seja obviamente verdade que a representação dos deuses egípcios recorre à combinação de formas humanas e animais, é errado dizer-se que um deus é «metade homem metade animal». Para além de imprecisa, esta expressão fica-se pelas aparências e, portanto, muito aquém do verdadeiro significado do fenómeno que consiste em descrever a natureza íntima de um deus.

$O$ texto que acompanha o leitor na sala do sarcófago tece, ao acaso, algumas considerações sobre o julgamento dos mortos. $O$ texto começa por referir que "a ideia de um julgamento final após a morte era para os Egípcios um momento de grande significado, pois simbolizava a passagem dos justos para a margem oeste do rio Nilo, onde todos viveriam felizes no tão almejado reino de Osíris". Uma tal afirmação, embora bela e perspectivando um cenário idílico, veicula, uma vez mais, uma imagem pouco precisa das representações relacionadas com a vida no Além. É certo que o julgamento dos mortos é um processo central das crenças do Além. O que não é de todo verdade é que este processo "simbolizava a passagem dos justos para a margem oeste do rio Nilo". Na verdade, no momento em que ocorre, já o defunto há muito que habita a margem ocidental. Para que o leitor compreenda o equívoco traçado pela afirmação, atente-se ao percurso que o defunto efectua ao longo do "Livro dos Mortos". Para Paul Barguet, que traduziu esta compilação de textos para a língua francesa, os primeiros capítulos (1-15) evocam a chegada do defunto à margem ocidental e o caminho para a necrópole. Ora, o julgamento do defunto é o tema do capítulo 125 (!) e ocorre após a reanimação do defunto e 
a saída para o dia (peret em heru), ao longo da qual o defunto visita o templo de Heliópolis e, integrando-se na barca solar do deus Ré, viaja para os Campos de laru e enceta uma peregrinação pelas cidades sagradas do Egipto. O julgamento do defunto não simboliza, portanto, "a passagem dos justos para a margem oeste do rio Nilo", o qual constitui o momento inaugural da viagem do defunto. $O$ que este momento assinala e simboliza é a justificação do defunto, ou seja, a sua transformação num deus e a sua admissão nas regiões mais secretas do mundo inferior onde se verificaria a sua regeneração e a participação nos mistérios de Osíris - ora estes mistérios que, não o esqueçamos, são o tema da própria exposição e são evocados explicitamente no título, "Os Mistérios do Além", afinal são esquecidos e o sentido perde-se. Voltaremos a esta questão que merece ser analisada em detalhe.

Também é referido que a "crença na imortalidade da alma assentava nos princípios da verdade, justiça e ordem». A denominada "crença na imortalidade da alma" é um conceito que nos transporta para o âmago das preocupações da egiptologia que, ao longo das últimas décadas, se tem esforçado por se "purgar» das contaminações ideológicas que recebeu, por herança, dos seus ilustres pioneiros do século XIX. Embora a designação de "alma" se possa encontrar em alguma literatura egiptológica mais desactualizada, actualmente a utilização deste termo é vivamente desaconselhada, como escrevia Louis Zabkar em 1975:

"The $\mathrm{Ba}$, as well as the cognate concepts of the $\mathrm{Ka}$ and Akh, has no exact equivalent in any modern, classical or semitic language. To translate the word $\mathrm{Ba}$ as "soul», as has been and still is done, not only does not render its fundamental meaning, but, by introducing a dualistic distinction between body and soul proper to some other philosophical systems, vitiates the very concept of man which the Ancient Egyptians held".(1)

Também os estudiosos das noções de akh e de ka advogam este cuidado no distanciamento em relação às crenças estrangeiras ao antigo Egipto, as quais são subrepticiamente introduzidas através do uso de termos imprecisos. Gertie Englund, por exemplo, demonstrou a especificidade existente entre os termos akh e ba, a qual se desvanece se continuarmos a adoptar genericamente os termos "alma" ou "espírito"(2) O conceito que os autores do texto que acompanha a exposição da Casa-Museu Teixeira Lopes utilizam não só é totalmente 
estrangeiro ao horizonte religioso do antigo Egipto, como reflecte uma etapa da egiptologia já ultrapassada.

Finalmente é ainda referido que "segundo o ideal de justiça divina ao lado da balança estava presente a "Grande Devoradora", um monstro híbrido de crocodilo, pantera e hipopótamo, pronto a devorar o defunto caso o coração tivesse um peso excessivo". Como qualquer pessoa familiarizada na terminologia das ciências naturais sabe, a designação «híbrido» nunca poderia ser aplicada a este "monstro». Em primeiro lugar esta designação é incorrecta para designar um fenómeno corrente na iconografia egípcia que consiste em combinar entre si representações distintas que são articuladas de modo críptico para evocarem determinadas qualidades. O monstro referido não é um híbrido no sentido em que não resulta da união de duas espécies diferentes (no caso até são enumerados três). A representação compósita de várias partes do corpo de animais é um recurso habitual da iconografia egípcia, cujo intuito não é o de criar "híbridos» ou "quimeras", mas sim o de caracterizar, através da representação, a natureza da entidade representada. Atente-se a este respeito, às palavras de Erik Hornung:

«Aucune de ces images ne révèle la forme véritable d'un dieu, et aucune n'est en mesure d'englober la richesse totale de sa nature - ce qui explique l'iconographie variable des dieux égyptiens, qui est rarament réduite à une forme fixe, canonique. Chaque image est une manière imparfaite de rendre un dieu visible, caractérisant sa nature et le distinguant des autres divinités."(3)

Além disso, o nome da fera também não está correcto, uma vez que o seu nome em egípcio é Ammut, termo que significa «A Devoradora de Mortos" e não a "Grande Devoradora".

\section{Os textos de divulgação}

O texto que divulga a iniciativa veicula uma ideia deturpada do verdadeiro peso da colecção egípcia do Museu de História Natural no contexto das colecções egípcias conservadas em Portugal, uma vez que refere que "estas 103 peças fazem dela a maior das colecções egípcias existentes na Região Norte e a segunda maior de Portugal, logo a seguir à do Museu Nacional de Arqueologia, em Lisboa". Como comecei por referir, não se pode simplesmente ignorar a colecção 
egípcia do Museu da Fundação Calouste Gulbenkian, a mais importante conservada no nosso país, além de que, com as suas mais recentes aquisições, o acervo egípcio do Museu da Farmácia também já superou o acervo portuense.

Também não é verdade, como afiança o mesmo texto de divulgação, que «é a primeira vez que ela (a colecção egípcia) é apresentada ao público na sua totalidade". Na verdade, continua a estar ausente dos olhos do público a múmia feminina que também faz parte da colecção egípcia do Museu e que aqui parece ter sido esquecida.

O folheto que divulga a exposição também não está isento de problemas. Em primeiro lugar há uma falta de uniformidade na legendagem das peças. Uma estatueta de Neit foi inadvertidamente colocada entre estatuetas funerárias, sem que a legenda que a acompanha lhe faça qualquer alusão. Como noutros textos "explicativos", o autor destas linhas introduz explicações pouco claras sobre a função das estatuetas funerárias: "As chauabtis são estatuetas funerárias que representam homens de várias profissões que deviam acompanhar o defunto e ajudá-lo nas tarefas quotidianas na vida do Além.»

Mais uma vez o autor revela dificuldades elementares de conhecimento da escrita hieroglífica. O termo chauabti é, sem lugar para dúvidas, uma palavra masculina. Ora o autor do texto de divulgação chama-lhe "as chauabtis". Também não é correcto dizer-se que estas estatuetas representavam homens de várias profissões. No Império Antigo e no Império Médio era de facto habitual munir o túmulo com estatuetas, geralmente de madeira, que representavam homens e muIheres a executar diversos ofícios, como o de oleiro, talhante, músico, cozinheiro ou até de ama. Ora, a criação deste tipo de estatuetas, que de facto se destinavam a executar as tarefas quotidianas, nada tem que ver com a função mágica dos chauabtis, cujo aparecimento só se verifica no Império Novo, ou dos posteriores uchebtis. Atente-se à definição, simples e escorreita, da função destes objectos feita por Saddik:

"As estatuetas de servos em forma de múmia tinham como tarefa levar a cabo os trabalhos necessários nos "dois campos dos justos" em substituição do proprietário do túmulo".(4)

O intuito destas estatuetas não era o de fornecer ao defunto servos com ofícios diferentes, como sugere o texto, mas unicamente o de trabalhar no campo. A sua função não era genericamente a de 
ajudar «nas tarefas quotidianas na vida do Além», mas sim a de assegurar os trabalhos agrícolas necessários especificamente para produzir alimento para o defunto.

A tabela cronológica patente no folheto introduz também alguns elementos problemáticos graves e exasperantes. Em primeiro lugar, a numeração das dinastias é feita por anteposição (é I dinastia e não dinastia I como aparece no folheto) e introduz elementos claramente erróneos. Dentro da Época Baixa, refere-se a existência dos faraós "Kusitas" em vez de "Cuchitas", os quais eram originários de Kuch e não de "Kus", como a inusitada expressão induz num leitor menos precavido. Em seguida refere que a " $1^{a}$ dominação persa" se estende da XXVII à XXX dinastia, quando, na realidade, apenas se circunscreve à XXVII dinastia. Na verdade, ao contrário do que afiança a tabela, a XXVIII, a XXIX e a XXX dinastias são autóctones. E na " $2^{\mathrm{a}}$ dominação persa", inexplicavelmente o tempo volta para trás, de volta à XXI dinastia. Curiosamente, para a dinastia lágida, o autor agora refere correctamente o ano 30 a. C. como sendo o fim do período ptolemaico, ao contrário da enigmática cifra de 32 a. C., que figura nas legendas da exposição.

\section{O tema da exposição}

Finalmente vale a pena desenvolver algumas considerações basilares a respeito do tema da exposição. O título desta induz no visitante a perspectiva de ir conhecer "Os Mistérios do Além no Antigo Egipto". É preciso aqui referir que o título permitia explorar a apresentação do espólio egípcio do Museu, quase todo ligado ao horizonte funerário, de modo a proporcionar ao público uma exposição temática que, para além de atractiva, poderia ser esclarecedora quanto ao significado das peças exibidas. Poder-se-ia desse modo realizar um percurso capaz de ilustrar ao visitante a complexidade e a extraordinária riqueza das práticas funerárias e do imaginário religioso do antigo Egipto associado ao Além. No entanto, apesar das potencialidades oferecidas pelo tema, a verdade é que os textos de apoio à exposição, para além de todas as falhas apontadas, parecem ter-se esquecido da centralidade que o título atribui às questões do Além dando atenção à "Magia e aos Amuletos", à "Vida após a Morte» (o único directamente relacionado com a morte), à "Vida Quotidiana", 
à "Religião egípcia e o culto aos deuses" e até ao "Egipto Copta" cuja relação com a exposição se depreende a partir de um único e muito danificado objecto.

Além do mais, embora possa parecer uma designação genérica e falaciosa, na verdade, o título reúne, de um modo simples e chamativo, duas noções egípcias fundamentais para compreender as crenças funerárias do antigo Egipto: a noção de "mistério" e a noção de "Além», as quais, longe de serem uma designação genérica, correspondem a noções muito precisas. A noção de "mistério", sechetá em egípcio, é fulcral nas crenças funerárias, pois é ela que determina e estrutura todo o ritual funerário. António Loprieno encara a noção de "mistério» como central para a manifestação do sagrado. Também Jan Assmann demonstrou que, no âmbito das crenças funerárias, o termo "mistério" confunde-se com a própria ideia de "cadáver", uma vez que era o carácter escondido e oculto da múmia que garantia a sua existência perene. Por outro lado, o termo "Além» traduz para a língua portuguesa a noção egípcia de Duat, o mundo inferior povoado pelos defuntos e pelas divindades ctónicas. A Duat era um território, por excelência, escondido e "misterioso», que abrigava do mundo a múmia e the facultava o contacto com as forças cósmicas que garantiam a sua renovação e regeneração. A Duat estava, deste modo, inseparável da ideia de mistério e, no imaginário egípcio, tinha profundas conotações com a regeneração que se desejava que ocorresse no mundo inferior.

O título da exposição fazia, portanto, prever um enquadramento conceptual bem delimitado. Secundariamente, para além de ser eficaz na delimitação das temáticas a trabalhar na exposição, o título tinha ainda a vantagem de ser atraente para o público em geral, habituado a associar o antigo Egipto aos temas da morte. Estas ideias feitas, em geral imprecisas e demasiado influenciadas pelo imaginário dos filmes de Hollywood, poderiam assim ser desconstruídas para que as conotações originais do imaginário da morte do antigo Egipto pudessem ser verdadeiramente apreciadas e compreendidas pelo público. Desconhecendo a real profundidade do próprio título da exposição, os responsáveis pela exposição mais não fizeram do que continuar a explorar o imaginário difuso e sombrio citado pelo título na mente do público leigo na egiptologia. Por outro lado, seria esclarecedor saber quantos (ou quais) egiptólogos integravam a equipa que gizou e montou a exposição. A que universidade pertencem, onde leccionam, que cuurrículo têm? 


\section{Considerações finais}

Pode argumentar-se que a divulgação a um público alargado obriga a uma simplificação que, para os entendidos, pode soar a um desvirtuamento. Não é essa a crítica que aqui fazemos. Ainda que não se levem em consideração os erros crassos e grosseiros divulgados na exposição, cujos autores, ao contrário da prática habitual de qualquer exposição, são inexplicavelmente omissos, a verdade é que, tal como se apresenta, este projecto se transformou, na melhor das hipóteses, num projecto de história civilizacional tal como era entendida nas mostras de curiosidades históricas do século XIX.

Para lá da óbvia não correspondência com o projecto anunciado, esta "mostra de curiosidades" nem sequer resulta numa divulgação que pretenderia atingir um público indeterminado; sabe-se que qualquer exposição deste tipo, onde o carácter científico é o primeiro critério, exige várias leituras, de menor ou maior erudição, mas nunca do senso comum e muito menos do equívoco. Longe de uma simplificação, os parcos e avaros textos apresentados transmitem uma imagem superficial, por vezes errónea e povoada por malentendidos, graIhas e distorções, onde os "Mistérios do Além no Antigo Egipto", o mote para a realização da exposição, não foram sequer entrevistos nem pelo público nem, o que é bem pior, pelos próprios organizadores da exposição.

Em face das evidentes lacunas apresentadas pelos textos que acompanham e promovem a exposição, embora nada seja referido acerca dos seus autores, não é de todo possível que tenha sido um egiptólogo a redigi-los. Importa pois averiguar como e em que circunstâncias a Universidade se envolveu num projecto tão pouco qualificado do ponto de vista científico. A importância e o impacto das questões técnicas que levantei poderão ser melhor compreendidas passando em revista as notícias veiculadas nos órgãos de comunicação social que ao evento dedicaram algumas linhas. A título de exemplo, em todas elas é insistentemente referido que a colecção egípcia do Museu de História Natural é «a segunda maior colecção egípcia em Portugal», o que não é correcto.

Certamente bem intencionados, alguns jornalistas chegam mesmo ao ponto de decalcar certos trechos dos prospectos da exposição: "chauabtis que representam homens de várias profissões que deviam acompanhar o defunto e ajudá-lo nas tarefas quotidianas na vida do Além", o que, como também já referi, constitui uma afirmação bastante 
imprecisa e reflecte uma compreensão insuficiente e deturpada sobre a real função destes objectos no Além. Citações como esta ilustram o alcance e a responsabilidade inerente à elaboração do material documental que acompanha a exposição. Uma exposição deste teor não pode ser apenas "agradável de ver» e deve ser acompanhada por um trabalho de divulgação credível, compatível com o tremendo interesse do público por esta área.

Os organizadores deste evento devem pois reflectir sobre este episódio que exemplifica os efeitos de uma atitude perante o património que desde há muito se encontra desactualizada e que actualmente já é anacrónica. O verdadeiro património de um Museu, sobretudo o de um museu universitário, como é o caso, é o conhecimento que é construído a partir dos objectos, os quais são entendidos sempre como documentos e não como meras relíquias usadas como pretexto para a exibição dos poderes ou para propaganda autárquica. Do ponto de vista científico, o único mérito desta iniciativa consiste justamente em nos recordar a todos, no seio da Universidade, para a responsabilidade inerente à gestão do património.

\section{Notas}

(1) Em ZAKBAR, "Ba», Lexikon der Ägyptologie, I, Otto Harrassowitz, Wiesbaden, 1975, col. 588

(2) Ver ENGLUND, «Akh - une notion religeuse dans l'Égypte pharaonique», Boreas, 11, Uppsala Studies in Ancient Mediterranean and Near Eastern Civilizations, Acta Universitatis Upsaliensis, Uppsala, 1978, pp. 207-208.

(3) HORNUNG, Les Dieux de l'Égypte: L'Un et le Multiple, Flammarion, Paris, 1992, p. 112.

(4) Em legenda da figura 105, SADDIK, "O Enterro", em Schulz e Seidel, O Egipto:

O Mundo dos Faraós, Köneman, 2001, p. 479.

Rogério Ferreira de Sousa 